\title{
Standardized annular assay of dual radioisotopes on a well type sodium iodide crystal
}

T. K. BELL

From the Medical Physics Department, Royal Victoria Hospital, Belfast

SYNOPSIS A procedure is described for the determination of the separate amounts of two gamma-emitting radioisotopes present simultaneously in large liquid volumes using an annulare cell placed over a standard well-type crystal of sodium iodide and a reference source of ${ }^{137} \mathrm{Cs} \cdot \overrightarrow{\overrightarrow{0}}$ This sensitive technique is illustrated with particular reference to the double radioisotope urinary excretion test, using orally administered ${ }^{57} \mathrm{CoB}_{12}$ bound to human gastric juice and ${ }^{58} \mathrm{CoB}_{12}$ simultaneously, for the differentiation between patients with intrinsic factor de-o ficiency and other causes of vitamin $B_{12}$ malabsorption.

The problem of determining the separate amounts of two radioactive isotopes emitting radiations of different energies in a sample containing both isotopes simultaneously has been discussed by Veall and Vetter (1958) and may be considered with reference to the assay of blood samples containing ${ }^{51} \mathrm{Cr}$ and ${ }^{59} \mathrm{Fe}$.

Blood samples are often restricted to about $5 \mathrm{ml}$ which may be readily accommodated in individual test tubes and counted in the well of a 2 in. crystal of sodium iodide. The procedure for ${ }^{51} \mathrm{Cr}$ and ${ }^{59} \mathrm{Fe}$ mixtures using a singlechannel instrument is usually one in which each test tube containing blood and standard solutions containing each radioisotope separately are assayed under conditions of discriminator bias or channel width to detect mainly the $1 \cdot 1$ and $1.29 \mathrm{Mev}$ gamma rays from ${ }^{59} \mathrm{Fe}$. The samples and standards are then recounted with appropriate conditions of discriminator bias or channel width to detect most of the $0.32 \mathrm{Mev}$ gamma rays from ${ }^{51} \mathrm{Cr}$. After correcting for background contributions the solving of two simultaneous equations, incorporating the measurements under the two sets of counting conditions, provides the individual amounts of each radioisotope present in the blood samples.

When assaying urine from a patient a volume of about a litre is usually available from a 24Received for publication 25 September 1969. hour urine collection, and Bell (1965) has $\overrightarrow{\overrightarrow{0}}$ shown that better counting performance for $a^{\exists}$ range of six radioisotopes may be obtained by assaying $400 \mathrm{ml}$ volumes in an annular cup placed over the crystal compared with assayingo $5 \mathrm{ml}$ in the well of the crystal.

However, it is not always convenient to accom modate $400 \mathrm{ml}$ volumes in separate annularo cups because of space and cost compared with test tubes. Hence one tends to count all theo samples in the same annular cup, rinsing it $\triangle$ out between samples in a fashion similar to the assay of $\beta$-emitting radioisotopes in a liquid sample $\beta$ counter type M6 $^{1}$. This procedure is ${ }^{\circ}$ straightforward when counting a single radio- $N$ isotope in the sample, but in order to minimize the number of times the annular cup has to beg filled during the assay of samples containingo two radioisotopes a standard procedure has been developed to ensure that the correct assay? conditions are maintained.

This procedure is outlined with particularo reference to the assay of ${ }^{57} \mathrm{Co}$ and ${ }^{58} \mathrm{Co}$ in urine $\mathbb{D}_{\overparen{D}}$ arising out of the study of $B_{12}$ absorption in patients using a dual isotope technique (Bell, $\frac{\Omega}{O}$ Bridges, and Nelson, 1965), but it may be applied to any two gamma-emitting radioisotopes of suitable gamma ray energy difference. Standard-s ization of the two assay conditions is obtaine 120th Century Electronics, Croydon, England 


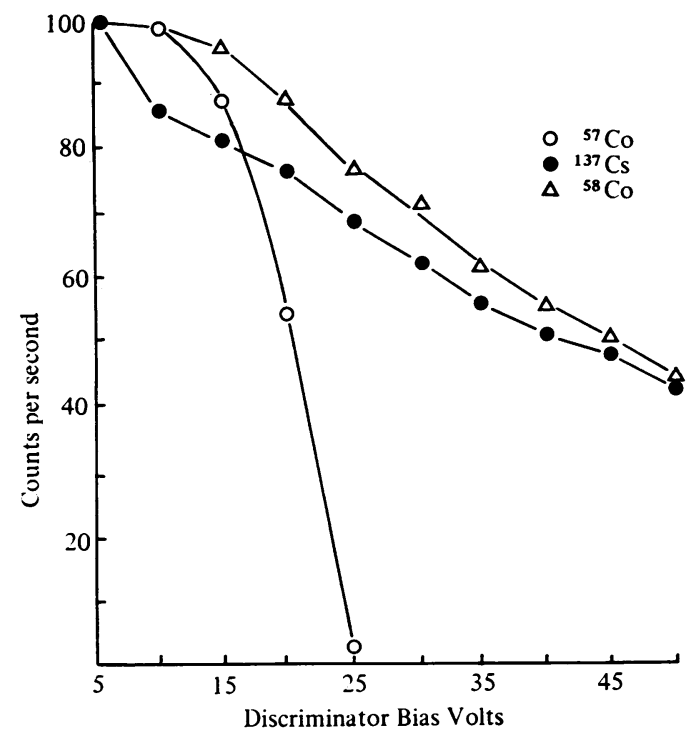

Fig. Normalized variation in counting rate with increasing discriminator bias per $400 \mathrm{ml}$ solutions of ${ }^{57} \mathrm{Co}$ and ${ }^{58} \mathrm{Co}$ in the annular cell and ${ }^{137} \mathrm{Cs}$ in a test tube in the well of the crystal using the integral mode of counting. by using a test tube containing ${ }^{137} \mathrm{Cs}$ which emits gamma rays of energy $0.66 \mathrm{Mev}$ compared with 0.12 and $0.81 \mathrm{Mev}$ from ${ }^{57} \mathrm{Co}$ and ${ }^{58} \mathrm{Co}$ respectively.

The problem is to determine the percentage of $\underline{\underline{0}}$ the ${ }^{57} \mathrm{CoB}_{12}$ bound to intrinsic factor, and ${ }^{58} \mathrm{CoB}_{12}$ doses excreted in the urine following the simultaneous oral administration of $0.25 \mu \mathrm{Ci}$ of these radioactive compounds to patients.

\section{Initial Setting Up}

The high voltage supply to the photomultiplier $\overrightarrow{\vec{\omega}}$ tube viewing the sodium iodide crystal and $\stackrel{?}{\Omega}$ amplifier gain are adjusted to give the integral용 spectrum for $400 \mathrm{ml}$ of ${ }^{57} \mathrm{Co}$ in the annular cup i between 5 and 30 volts (V) discriminator bias. Using these values of high voltage and amplifier $\omega_{\omega}$ gain, the integral spectra for $400 \mathrm{ml}{ }^{58} \mathrm{Co}$ in the ${ }^{\circ}$ annular cup and $0.2 \mu \mathrm{Ci}^{137} \mathrm{Cs}$ in a $1.0 \mathrm{ml}$ volume 을 sealed in a test tube of $\frac{5}{8}$ in. diameter assayed in the well of the crystal are also obtained. The counts registered on an associated scaler are normalized to $100 \%$ at $5 \mathrm{~V}$ discriminator bias $\vec{\theta}$ as shown in the Figure. The actual counts detected $\supset$ from the ${ }^{137} \mathrm{Cs}$ standard source in 100 seconds in the well of the crystal are noted both at 5 and $35 \mathrm{~V}$.

\section{Assay of ${ }^{57} \mathrm{Co}$ and ${ }^{58} \mathrm{Co}$}

The sequence of counting is carried out as indicated in the Table with the ${ }^{137} \mathrm{Cs}$ standard source assayed in the well of the crystal, and the samples? and separate standards are made up in $400 \mathrm{ml}$ water containing $10 \%$ of the ${ }^{57} \mathrm{Co}$ and ${ }^{58} \mathrm{CoB}_{12}$. doses respectively assayed in the annular cup, $\delta$ and the averages of the two 300 -second counting periods are considered for the sample counts 9 at discriminator settings of 5 and $35 \mathrm{~V}$. The ${ }^{137} \mathrm{Cs}$ standard need only be counted for 100 을 seconds since the quantity of radioactivity is chosen to provide a high counting rate.

\section{Calculation}

Consider the Table where the data obtained at $\stackrel{\mathscr{P}}{+}$ 5 and $35 \mathrm{~V}$ discriminator bias settings are pre- 0 sented in symbolic form together with an example $\stackrel{P}{\circ}$ using data obtained from the investigation of $\stackrel{\mathcal{Q}}{\mathcal{Q}}$ a patient. The small letters indicate the ap- $\underset{\mathcal{D}}{\mathbb{Q}}$ propriate average observed counts in the counting ${ }_{\sigma}$ periods. Steps 14,15 , and 16 may be omitted if the assay procedures are carried out under:응 conditions in which the backgrounds do not vary greatly. These requirements are usually $\frac{0}{\partial}$ assisted by keeping the ${ }^{137} \mathrm{Cs}$ standard in a lead
Table Standardized counting procedure

${ }^{1}$ The counts observed from the ${ }^{137} \mathrm{Cs}$ are shown in brackets (d) and (g) to indicate that they are used only to check the instrument settings and are not used in calculating the percentage of the ${ }^{67} \mathrm{Co}$ and ${ }^{58} \mathrm{Co}$ doses excreted. 
shield, with walls at least $2.5 \mathrm{~cm}$ thick, when not required.

Since the $35 \mathrm{~V}$ discriminator bias excludes the gamma rays from ${ }^{57} \mathrm{Co}$ the simultaneous equations to be solved are simplified. Thus the percentage of the ${ }^{58} \mathrm{CoB}_{12}$ dose excreted is given by $x=\frac{\mathrm{NT}}{40 \mathrm{C}}$. The percentage of the ${ }^{57} \mathrm{CoB}_{12}$ dose excreted is given by $y=\left(M-\frac{B N}{C}\right) \frac{T}{40 A}$.

The ratio of the amounts of ${ }^{57} \mathrm{Co}$ and ${ }^{58} \mathrm{Co}$ excreted is obtained by dividing $y$ by $x$.

Using the figures quoted in the Table, the percentage of ${ }^{58} \mathrm{CoB}_{12}$ excreted is given by

$\frac{1017 \times 1020}{40 \times 9303}=2.8 \%$. The percentage of ${ }^{57} \mathrm{CoB}_{12}$ excreted is given by

$\left(11763-\frac{13425 \times 1017}{9303}\right) \times \frac{1020}{40 \times 24247}=$ $10 \cdot 8 \%$. The ratio of ${ }^{57} \mathrm{Co}$ to ${ }^{58} \mathrm{Co}$ equals 3.9 .
It will be noted that the counts from the ${ }^{137} \mathrm{Cs}$ standard do not enter into the calculation: of the fractions of ${ }^{57} \mathrm{Co}$ and ${ }^{58} \mathrm{Co}$ excreted ino the urine. The ${ }^{137} \mathrm{Cs}$ standard serves only toof indicate that the correct discriminator biaso conditions have been properly selected in turn and provides an immediate check for the in experienced operator at the time of assay ande from day to day due to its long half life of $30 \underline{\underline{\underline{\sigma}}}$ years.

References

Bell, T. K. (1965). Annular counting of radioisotopes in large liquid volumes on a well type scintillation crystal ofo sodium iodide. Brit. J. Radiol., 38, 886-887.

Bell, T. K., Bridges, J. M., and Nelson, M. G. (1965). Simulo taneous free and bound radioactive vitamin $B_{1}$, urinaryin excretion test. J. clin. Path., 18, 61 1-613.

Veall, N., and Vetter, H. (1958). Radioisotope Techniques int Clinical Research and Diagnosis. ch. 6. Butterworth, London. 